\title{
Animal health and welfare planning improves udder health and cleanliness but not leg health in Austrian dairy herds
}

\author{
Lukas Tremetsberger, ${ }^{1}$ Christine Leeb, and Christoph Winckler \\ Division of Livestock Sciences, Department of Sustainable Agricultural Systems, University of Natural Resources and Life Sciences, \\ Gregor-Mendel-Str. 33, 1180 Vienna, Austria
}

\begin{abstract}
Animal health and welfare planning is considered an important tool for herd management; however, its effectiveness is less well known. The aim of this study was to conduct animal health and welfare planning on 34 Austrian dairy farms and to evaluate changes in health and welfare after $1 \mathrm{yr}$. After an initial assessment using the Welfare Quality protocol (Welfare Quality Consortium, Lelystad, the Netherlands), results were reported back to the farmers. Health and welfare area(s) in which both the farmer and the researcher regarded improvement as important were discussed. Management practices and husbandry measures were chosen according to the respective farm situation. One year after interventions had been initiated, farms were reassessed, and the degree of implementation of improvement measures was recorded. The average implementation rate was $57 \%$ and thus relatively high when compared with other studies. High degrees of implementation were achieved related to cleanliness and udder health, at 77 and $63 \%$, respectively. Intervention measures addressing udder health were mostly easy to incorporate in the daily routine and led to a reduced somatic cell score, whereas this score increased in herds without implementation of measures. The decrease in cows with dirty teats was more pronounced when measures were implemented compared with control farms. The implementation rate regarding leg health (46\%) was comparably low in the present study, and leg health did not improve even when measures were implemented. Lying comfort, social behavior, and human-animal relationship did not require interventions and were therefore seldom chosen by farmers as part of health and welfare plans. In conclusion, the structured, participatory process of animal health and welfare planning appears to be a promising way to improve at least some animal health and welfare issues.
\end{abstract}

Received November 7, 2014.

Accepted June 13, 2015.

${ }^{1}$ Corresponding author: lukas.tremetsberger@boku.ac.at
Key words: animal health and welfare planning, dairy cow, implementation, Welfare Quality

\section{INTRODUCTION}

High levels of animal health and welfare are important for successful dairy cattle farming. However, health concerns such as lameness and mastitis have repeatedly been described during the last decades. Several studies indicate that foot and leg health (e.g., prevalence of lame cows) is at an unacceptable level (Whay et al., 2003) and has not improved appreciably during this time (Clarkson et al., 1996; Haskell et al., 2006; Dippel et al., 2009). Furthermore, levels of milk SCC and mastitis incidence are both relevant for welfare and farm economics (Huijps et al., 2008), thus emphasizing the importance of improving udder health (Green et al., 2007; Ivemeyer et al., 2008, 2012). The substantial between-farm variability of these health problems indicates that achieving or maintaining a high health state is possible within existing systems.

Improvement in health and welfare may be facilitated by approaches based on education, enforcement (i.e., legislation), or encouragement (Whay and Main, 2010). Advisory activities in livestock production have frequently been based on the dissemination of knowledge in a top-down approach and on providing technical information for improvement (Whay and Main, 2010). However, more recently, participatory involvement of the farmer has been considered crucial for successful interventions (Whay and Main, 2010; Main et al., 2012). For instance, the fact that a lameness control plan was only poorly implemented in UK dairy farms could be attributed to insufficient integration of farmers (Bell et al., 2009). On the contrary, encouraging farmers to take action to improve undesirable health and welfare states has proven successful in the past with respect to udder and leg health. For example, providing information on how to tackle lameness and supporting farmers in formulating a farm-specific lameness action plan rather than imposing predefined control measures by the researchers resulted in a decrease of lameness 
prevalence by approximately 12 percentage points in UK dairy herds (Main et al., 2012). Similarly, in a 2-yr study among 65 Swiss dairy farms, when farmers were included in the development of suitable improvement measures, treatment incidence of mastitis decreased by about one-third without deterioration of udder health (Ivemeyer et al., 2008).

Animal health and welfare planning constitutes an approach to integrate farmers' participation and encouragement. It was first introduced into British farming (Sibley, 2002) and made compulsory in most UK assurance schemes commencing in 2000 (Main et al., 2001). Several intervention studies (e.g., Bennedsgaard et al., 2010; Brinkmann and March, 2010; Ivemeyer et al., 2012) also applied the animal health and welfare planning approach. These studies emphasize the initial assessment and evaluation of health and welfare by an external person, implementation of farm-specific measures, and constant review and adaptation of measures as key aspects. The structured process includes farmer ownership of goals and measures, involvement of all relevant people, and the acknowledgment of good aspects on the farm (Vaarst et al., 2011; Tremetsberger and Winckler, 2015).

Until now, attempts to improve dairy cattle health and welfare have focused on the reduction of negative health states. However, the scientific concept of animal welfare reflects a comprehensive view, including the animals' emotional state (Duncan, 1996) and their ability to behave naturally (Fraser et al., 1997). On-farm studies addressing welfare improvement in terms of the animals' behavior such as human-animal relationship (HAR) and social behavior are rare, however. To our knowledge, so far only Gratzer (2011) has considered these aspects in dairy health and welfare planning.

The aim of the present study was to carry out animal health and welfare planning on 34 Austrian dairy farms and to evaluate changes in a range of indicators that reflect the multidimensional nature of animal health and welfare.

\section{MATERIALS AND METHODS}

\section{Study Design and Farm Selection}

The study was conducted from December 2011 to April 2013 on 34 dairy farms in 3 federal states in Austria (Lower Austria, Upper Austria, and Styria). Because the aim was to motivate farmers to implement improvement measures, farmers had to express initial motivation to take part. Recruitment of farms took place through various channels: in 3 districts in Lower Austria, farms were provided with a one-page information leaflet distributed by the milk recording service or by 3 veterinary surgeons. Farmers interested in participating could then approach the researcher directly. Within each region, some farms were included in the study after they had been informed by participating farmers, following a so-called snowball approach (Micheel, 2010).

All participating farms were family-run and averaged $39 \pm 21$ ha (mean \pm SD) in size. On all farms, dairy cows were kept in cubicle housing systems (average age of the housing system: $9.1 \pm 5.3 \mathrm{yr}$ ). Cows did not have access to pasture, but 11 herds had permanent access to a concrete outdoor run. The predominant breed was Austrian Fleckvieh, with 25 herds consisting of more than $90 \%$ of this breed. The remaining 9 farms kept either Holstein Friesian (2 farms), Brown Swiss (3 farms), or a mixture of all 3 breeds (4 herds).

\section{Data Collection}

During the study period, 3 visits in total to each farm took place. Data collection was carried out by one researcher (LT). The baseline health and welfare status was assessed during the first farm visit (winter 2011-2012; year 0). A second farm visit $55 \pm 26 \mathrm{~d}$ (mean \pm SD) after the initial assessment was used for developing the animal health and welfare plan (winter/ spring 2011-2012; see below), during which improvement measures were initiated (i.e., health and welfare planning). Final data collection took place $423 \pm 29 \mathrm{~d}$ after the health and welfare planning visit (year 1). On average, $368 \pm 11 \mathrm{~d}$ elapsed between the health and welfare planning visit and the final visit.

Data collection was based on the Welfare Quality assessment protocol for dairy cattle, which relies, largely, on animal-based measures (Welfare Quality, 2009). The measures can be grouped into parameters assessed directly on the animal (observation of social behavior, avoidance of an approaching human, and clinical examination of the animals) or assessed through routinely collected herd data (e.g., milk SCC, mortality rates). A detailed description of the assessment procedure and the definitions of the parameters can be found in Welfare Quality (2009). Beyond the Welfare Quality assessment protocol, data collection was complemented by indicators of metabolic health (e.g., percentage of animals with a milk fat:protein ratio $>1.5$ as indicator of risk of ketosis; Table 1). This was done to collect detailed information about herd health status needed for detailed feedback on the farms. Similarly, dirtiness of teats was recorded more in detail (slightly and severely dirty teats) to be more precise in discussing possible interventions for increasing teat cleanliness. Additionally, SCS and the percentages of animals with a SCC $>100,000$ and $>400,000$ cells $/ \mathrm{mL}$, respectively, were 
included in the assessment protocol to obtain a broader picture of udder health.

These animal-based measures were complemented by the assessment of some resource-based parameters and management procedures using an interview with the farmer on the day of the assessment. All parameters were expressed at the herd level (e.g., percentage of lame animals). All but one of the farms participated in the nationwide milk recording scheme, which provided data on SCC and milk constituents, as well as average milk yield, average number of lactations, and herd size. The farm not participating in the milk recording scheme was excluded from the respective analyses.

\section{Health and Welfare Focus Areas}

Health and welfare indicators were used at the singlemeasure level and allocated to 6 focus areas (Table 1). Due to low prevalences, some indicators of disease (e.g., percentage of cows with nasal discharge) and the frequency of collisions with housing equipment during lying down were not considered as part of the health and welfare plans in the present study.

\section{Health and Welfare Planning Process}

The second farm visit was dedicated to the implementation of a health and welfare plan. For this purpose, data obtained from the first farm visit were reported back to the farmer using a written report. This report included presentation of farm-specific data benchmarked against the mean of peer farms. The visits for implementation of the plan started after 10 farms had been assessed, whose baseline situation was used as the benchmark. The benchmark data were updated after having assessed 20 and 30 farms; however, it did not change substantially in the course of the implementation visits.

The report was presented to each farmer by the researcher, and all focus areas described in Table 1 were subsequently discussed. In a first step, farmers chose one or more focus areas where action was regarded as important and the farmers also decided on which areas to prioritize. Specific, quantifiable aims were agreed upon; for example "reducing milk somatic cell count," "reducing lameness prevalence," or "reducing agonistic interactions." Prior to the visit, a list of potential improvement measures was developed based on a review of scientific literature, recommendations for good farming practice, and expert opinion. This list comprised interventions regarding management (e.g., teat disinfection, provision of bedding) as well as resources (e.g., protective gates for concentrate dispenser, rubber flooring), grouped into several sub-areas (e.g., cow hygiene, feeding; Table 2). During the discussion, farmers chose measures that were relevant to their situation and appeared to be suitable to achieve their chosen aim. Implementation of measures (yes or no) agreed in the health and welfare plans was recorded using a questionnaire and a resource checklist during the third farm visit (i.e., second data assessment visit).

\section{Statistical Analyses}

All statistical analyses were carried out at the farm level using the statistical computing software R (R Core Team, 2013). Farm characteristics in year 0 and year 1 were compared using $t$-tests. For analysis of the effectiveness of the health and welfare planning approach, farms were allocated to 1 of 3 groups per focus area. The "implementation group" consisted of farms implementing measures that had been discussed, chosen, and written down as measures for a specific focus area in the animal health and welfare plan. Farmers who had agreed on measures and documented them in their plan but did not implement them were treated as a "nonimplementation group." The "control group" consisted of farms that did not choose the respective focus area.

Multilevel mixed models were applied with health and welfare indicators as response variables and farm as random factor using the lme-function in $\mathrm{R}$ (Pinheiro et al., 2014). The effects of group affiliation (implementation vs. nonimplementation vs. control) and assessment time (year 0 vs. year 1) and their interaction were used as factors. In the case of too few farms (less than $10 \%$ of the sample, i.e., 4 farms) in the "nonimplementation" group (focus areas udder health, cleanliness, and social behavior/HAR), comparisons were only carried out only between control and implementation groups. For post hoc comparisons including all 3 groups, Tukey's multiple comparison correction was applied. Residuals were checked graphically for normal distribution by Q-Q plots and data were transformed where necessary. Square-root transformation was used for the indicators "risk of acidosis," "risk of ketosis," "overall lame," "dirty udder," "dirty hindquarter," "lying outside," and "median ADF" (median avoidance distance at the feeding rack, cm). The indicators "SCC400" (\% of animals with SCC >400,000 cells/mL), "mild integument alterations," "lying down," and "agonistic interactions" were log-transformed. A normal distribution was not achieved for the indicator "very lean" and therefore the indicator was not considered further in the analyses. The means given in the results are based on the nontransformed data, whereas the $P$-values were calculated using the transformed variables as described above. 


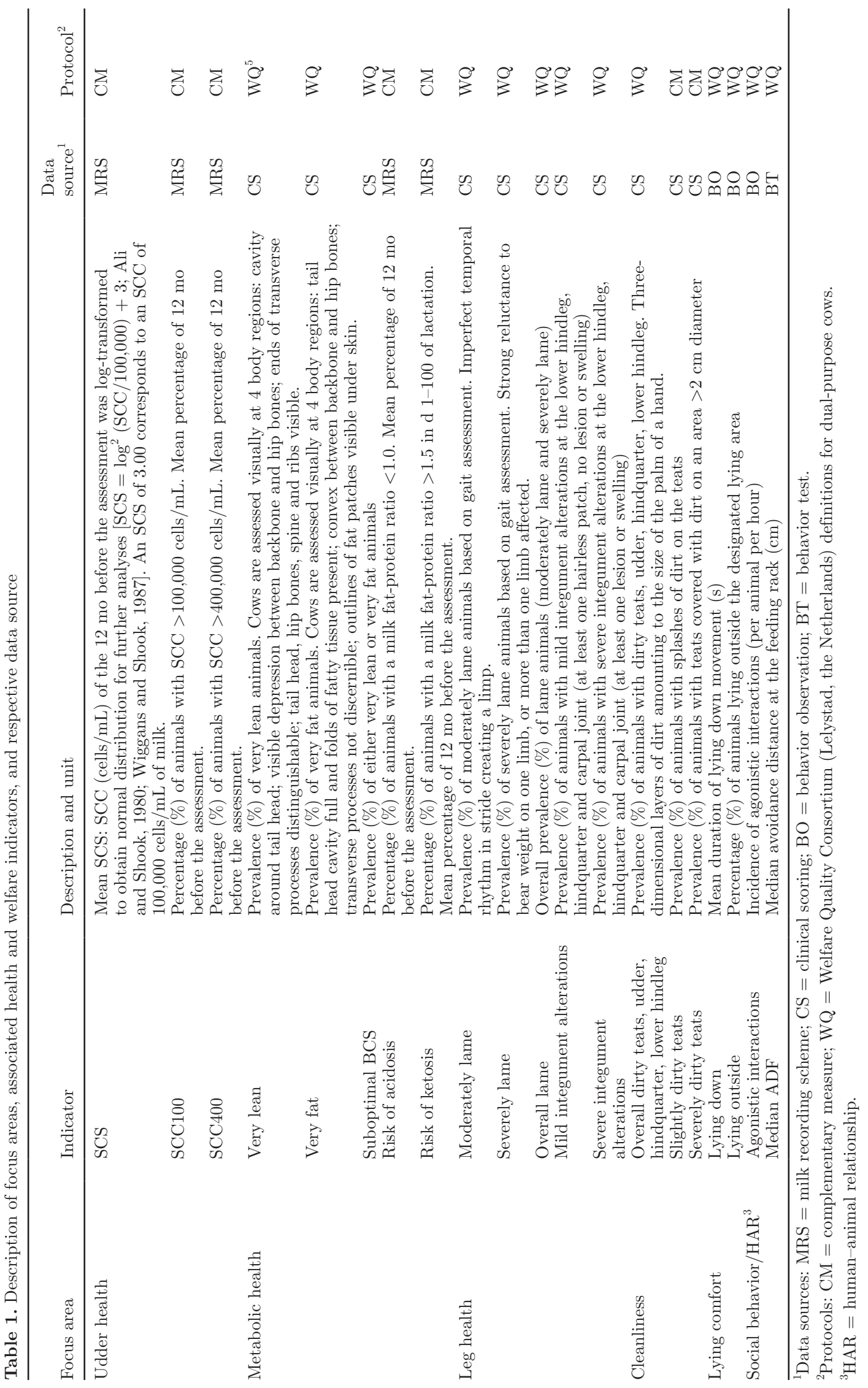


Table 2. Examples of improvement measures assigned to health and welfare focus areas and sub areas

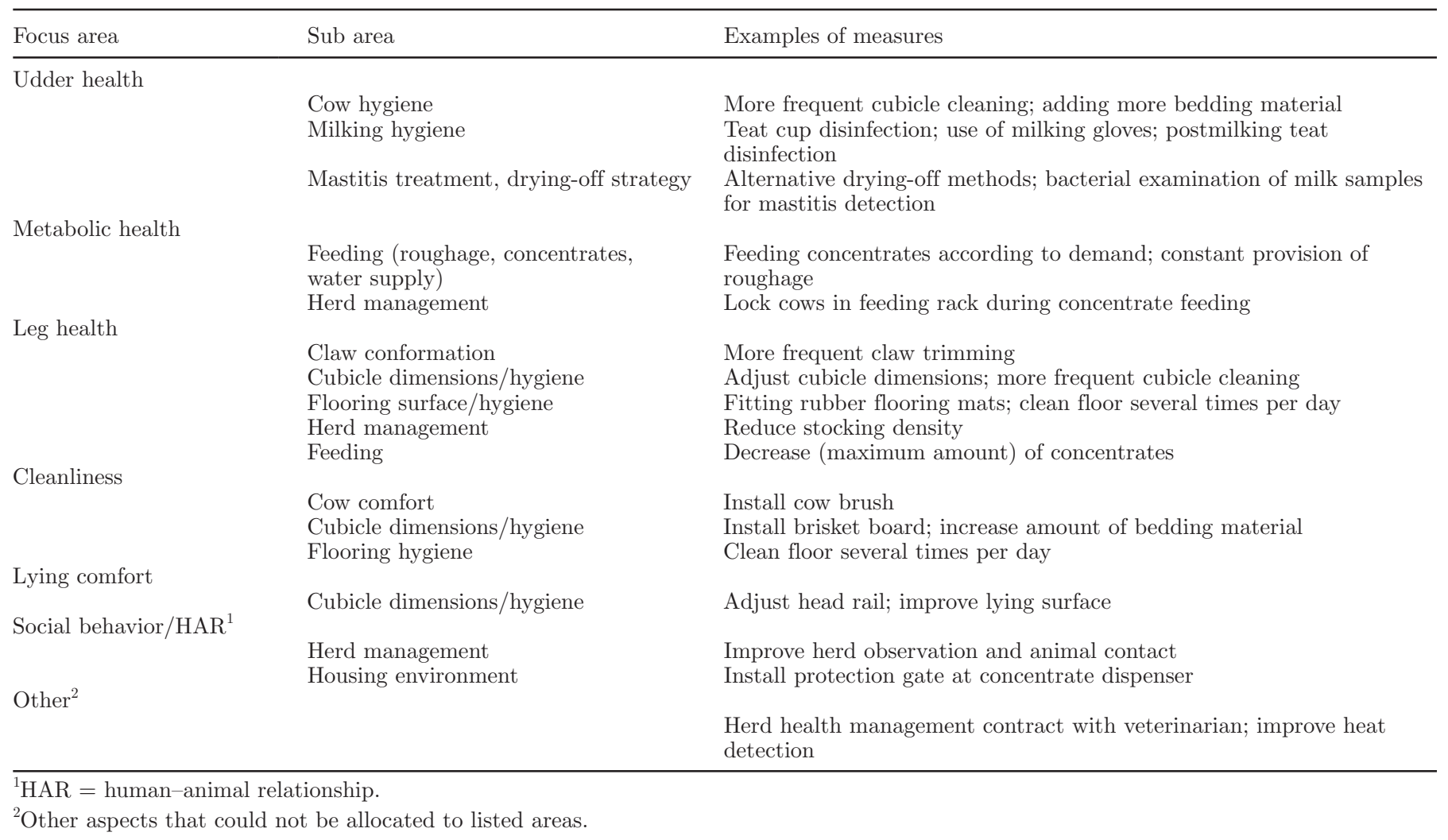

\section{RESULTS}

\section{Farm Characteristics}

Mean baseline herd size was $35 \pm 7$ cows (mean \pm SD) and did not change significantly during the study (year 1: $36 \pm 8$ cows). Mean milk yield per lactation was $8,321 \pm 951 \mathrm{~kg}$ and $8,478 \pm 1,047 \mathrm{~kg}$ in year 0 and year 1 (not significant), respectively. Herd age and average lactation number remained unchanged at $4.9 \pm$ $0.5 \mathrm{yr}$ and $3.4 \pm 0.6$ lactations, respectively.

\section{Aims and Implemented Measures for all Focus Areas}

All health and welfare focus areas were discussed on all 34 farms (Table 3). A median number of 3 focus areas (range 1-4) were identified per farm. Metabolic, leg, and udder health were most frequently chosen, whereas lying comfort and social behavior/HAR were rarely selected. Approximately $80 \%$ of the measures included related to changes in management practices; the remaining $20 \%$ addressed modifications of existing housing equipment or installation of new equipment.

All except one farm implemented measures (median of 2 focus areas per farm; range 1-4). Across all areas, in total 112 measures were implemented, with a median of 3 measures (1-8) per farm (Table 3), resulting in an overall degree of implementation of $58 \%$ (95\% CI: $26-$ $83 \%)$. Across all implemented measures, $56 \%$ (37-74\%), $15 \%(0-32 \%)$, and $29 \%(10-48 \%)$ were changes in daily management routines, occasional management routines, and changes to the housing system, respectively (Table $3)$. Measures that resulted in changes in daily working routines (e.g., postmilking teat disinfection) were frequently implemented in the focus areas cleanliness, metabolic health, and udder health. A large proportion of measures that needed to be implemented only once (e.g., adjusting cubicle dimensions) were found in the focus areas lying comfort and social behavior/HAR. In the focus area leg health, more than $60 \%$ of the implemented measures were occasional changes (e.g., more frequent claw trimming).

\section{Baseline Health and Welfare State}

For most parameters, the baseline situation (year 0) did not differ between groups. All implementation groups had a numerically less favorable mean baseline situation than the respective control herds. Mean baseline SCS and the overall prevalence of dirty teats were significantly higher in implementation herds than in control herds ( $P=0.049$ and $P=0.050$, respectively). 


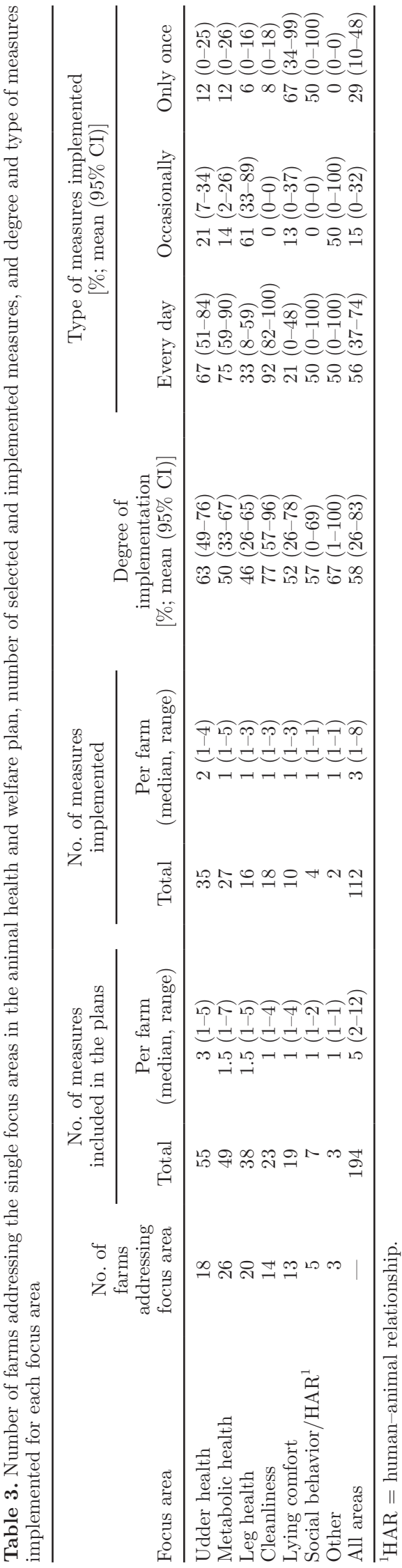

\section{Changes in Animal Health and Welfare from Year 0 to Year 1}

Regarding udder health, mean SCS decreased numerically in the implementation group, whereas it increased significantly in control herds $\left(P_{\text {group } \times \text { year }}=0.013\right.$; Table 4). A similar pattern was observed for the percentage of cows with a SCC exceeding 100,000 cells $/ \mathrm{mL}\left(P_{\text {group } \times \text { year }}\right.$ $=0.007)$. The percentage of cows with a SCC greater than 400,000 cells/mL remained unchanged in the implementation herds, whereas it increased in the control group $\left(P_{\text {group } \times \text { year }}=0.034\right)$. Regarding metabolic health, percentages of animals with a risk of ketosis $\left(P_{\text {year }}=\right.$ $0.035)$ and suboptimal BCS $\left(P_{\text {year }}=0.032\right)$ decreased over time in all 3 groups. No significant changes were observed for the prevalence of lame cows. Across all herds, prevalence of severe integument alterations (i.e., at least one lesion or swelling) increased from year 0 to year $1\left(P_{\text {year }}=0.025\right)$.

In the focus area cleanliness, a significant group $\times$ time interaction $\left(P_{\text {group } \times \text { year }}=0.049\right)$ was observed for the overall prevalence of dirty teats. We observed an overall decrease from year 0 to year $1\left(P_{\text {year }}<0.001\right)$, but the reduction was more pronounced on implementation farms. When the degree of dirtiness of teats was considered, mean prevalence was lower in year 1 for both slightly and severely dirty teats $\left(P_{\text {year }}<0.001\right.$ and $P_{\text {year }}=0.003$, respectively), and implementation herds had a higher prevalence of slightly dirty teats than control herds $\left(P_{\text {group }}=0.029\right)$. As for the overall prevalence of dirty teats, the reduction in the percentage of severely dirty teats was more pronounced for implementation farms $\left(P_{\text {group } \times \text { year }}=0.017\right)$. We detected no changes in measures of lying comfort. Implementation herds showed a higher average incidence of agonistic interactions than control herds $\left(P_{\text {group }}=0.049\right)$.

\section{DISCUSSION}

Improvement measures regarding husbandry and management were implemented to a relatively high degree, leading to a significant improvement of udder health and cleanliness of teats. Furthermore, the percentages of animals with suboptimal body condition and risk of ketosis were reduced in all herds.

With a mean of 35 cows, the participating farms kept considerably more cows than the average Austrian dairy farm, with a mean herd size of 13 dairy cows (BMLFUW, 2012). This above-average herd size was desirable to minimize the effect of single animals on herd-level prevalences. At the same time, these farmers might be more willing than the average farmer to implement changes in housing and management to improve animal health and welfare. However, farmers 


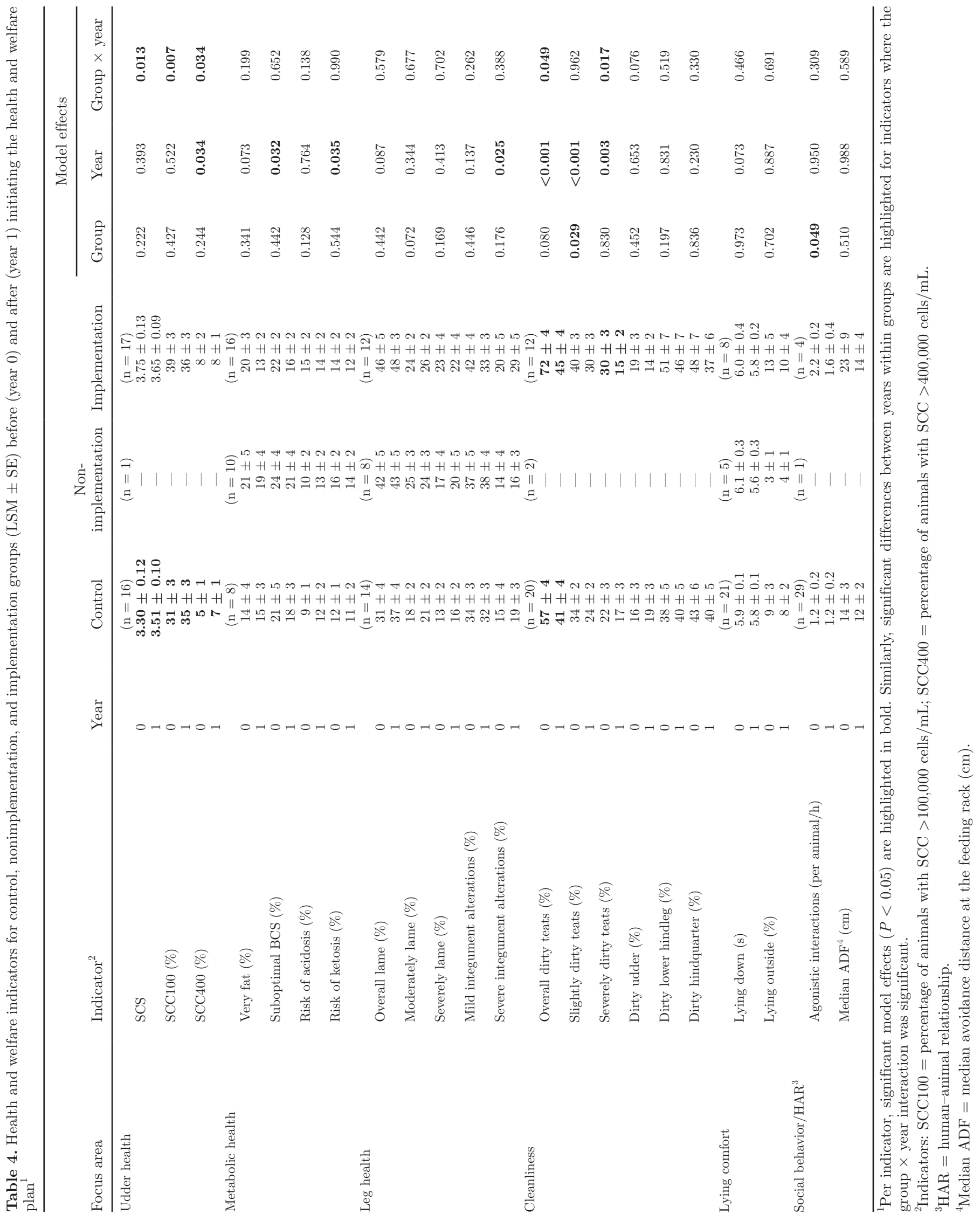


participated on a voluntary basis and one of the main criteria was therefore the motivation to enroll in a health and welfare improvement project. In general, the alterations made to management and housing systems on the study farms would also be applicable to small to medium-sized herds.

In the present study, the baseline situation for some health and welfare indicators was poorer in the implementation and nonimplementation groups than in the respective control herds. This reflects the aim of the study, which was to mimic advisory activities where farms with an already satisfactory level would not need action. Furthermore, the study aimed at improving negative health and welfare situations and not at improving the average farm or farms with an already high health and welfare state. Due to the setup of the study, it was not possible to blind the assessor regarding the allocation of the farms to the groups. However, the second on-farm assessment (year 1) was performed without recalling the results from the previous assessment or the chosen focus areas of the respective farm, in order to minimize a possible bias. Furthermore, on most farms, all animals were assessed, thus keeping a potential sampling bias small.

With an implementation rate of $57 \%$, measures in management and housing were implemented to a similar or higher degree compared with other intervention studies. Following a similar planning approach, Gratzer (2011) obtained the same implementation rate during a 1-yr herd health and welfare planning study among 39 Austrian organic dairy farms. Reasons for good acceptance of health and welfare plans may be seen in the structured, participatory process as well as in the farm-specific aims and interventions (Tremetsberger and Winckler, 2015). In contrast, in one of the few other studies that applied the Welfare Quality assessment protocol (in beef fattening farms), the uptake of measures proposed by the researchers was low, and health and welfare indicators did not change during the 6-mo study period (Kirchner et al., 2014). This might have been due to a more prescriptive advisory approach and the rather short duration of the study.

In the present study, as in Gratzer (2011), implementation rates varied between different focus areas. In total, 77 and $67 \%$ of the projected measures for the focus areas cleanliness and udder health were implemented, respectively. The implementation rate for udder health measures was similar to that in Gratzer (2011) and Green et al. (2007), where at least $66 \%$ of the farms implemented more than $33 \%$ of the measures, and greater than the rate of $43 \%$ observed by Brinkmann and March (2010). A relatively low uptake was found for measures relating to improvements in foot and leg health in the present study, in agreement with Barker et al. (2012) and Bell et al. (2009), who observed a similar degree of implementation (31\%), and "less than satisfactory" implementation rates, respectively. Higher rates were reported by Gratzer $(2011 ; 53 \%)$ and Brinkmann and March (2010) for a lameness intervention study in Germany, where after approximately $1 \mathrm{yr}, 11$ out of 21 farms had implemented more than two-thirds of the measures. However, unlike in Brinkmann and March (2010), farmers participating in the present study had to allocate their efforts to several focus areas within the 1-yr period. Similar to Gratzer (2011), measures relating to social behavior were seldom chosen and implemented by the farmers in the present study.

The implementation of measures developed during the planning process improved udder health state and teat cleanliness on the participating farms. Following interventions, SCS as well as the percentages of animals with SCC exceeding 100,000 and 400,000 cells/mL decreased in the implementation herds, whereas they increased in the control group. Baseline udder health was on a moderate level as regards, for example, SCC (Bennedsgaard et al., 2010; Ivemeyer et al., 2012). Unfortunately, unlike Green et al. (2007), we were not able to include treatment incidences in our analysis, as data were unreliable due to implausible within-farm variation in treatment incidences as well as incomplete farm records. It has been shown that farms with low health status have a higher potential for improvement and might therefore be easier to enhance (Green et al., 2007; Ivemeyer et al., 2009). In accordance with Green et al. (2007), who achieved a $20 \%$ reduction in clinical mastitis incidence, one reason for the effects found in this study might be the high implementation rate of agreed measures within this area compared with areas such as leg health. The high degree of implementation related to udder health could result from high awareness of the negative health consequences of impaired udder health (e.g., reduced milk yield, treatment costs, replacement costs), at least when compared with lameness (Whay et al., 2003). The measures discussed and agreed upon with regard to udder health may have been relatively easy to implement and well defined, which facilitated the incorporation of measures into the farm routine. All measures regarding udder health were management changes and about two-thirds of the measures affected the daily working routine, which required small capital investments.

Farms that implemented measures addressing cleanliness achieved a more pronounced reduction in the prevalence of overall dirty teats as well as severely dirty teats than control farms. Applying good management practices, especially bedding management, has been 
shown to be beneficial for teat and teat tip cleanliness (Plesch and Knierim, 2012). Implementation farms may have aimed more specifically at a reduction of severe dirtiness, as this poses a greater health risk, for example, for udder health (Schreiner and Ruegg, 2003; Ellis et al., 2007).

For both udder health and cleanliness, the response of nonimplementation farms (i.e., farms that discussed but did not implement any of these measures) could not be tested because of too few farms in the nonimplementation groups. It might be expected that farmers who decided to take action but did not initiate the agreed interventions could still have affected the animals; for example, by increased awareness of health problems or by introducing changes other than those included in the health plan. However, for the focus areas where the distinction between nonimplementation and implementation was possible (i.e., metabolic health, leg health, lying comfort), no differences between the 3 groups were obtained. Valid conclusions on a lack of effect would have to be drawn from larger samples, but in our data we did not find any indication that nonimplementation farms benefitted from the mere discussion of the respective animal health and welfare planning issues.

However, there were some indications that, across groups, the mere involvement in the study affected the behavior of the farmers, known as "Hawthorne effect" (Whay et al., 2012). For example, the proportion of animals with slightly dirty teats generally decreased within the study period. This may be explained by an increased general awareness regarding cleanliness following the process of health and welfare planning. March et al. (2014) reported a reduction in dirtiness of udders and bellies, even when the area was not selected as specific aim for improvement. In the present study, however, cleanliness of other body regions was not improved, presumably because no direct relevance for animal health and welfare was perceived. Regarding metabolic health, changes were observed across all farms irrespective of whether the farmers had chosen the respective focus areas. The percentage of cows with a risk of ketosis (milk fat:protein ratio $>1.5$ in the first $100 \mathrm{~d}$ of lactation) as well as the prevalence of cows with suboptimal body condition (very fat and very lean cows) decreased in all groups, indicating an improved periparturient metabolic situation (Roche et al., 2009). Furthermore, for control and nonimplementation farms, carryover effects of interventions in other focus areas could have occurred; however, quantifying such influences on other areas is challenging.

Severe integument alterations increased across all farms within the 1-yr period. It is not clear what might have caused this development, because knowledge on how integument alterations such as hairless patches, lesions, and swellings change in type and severity over time is scarce (Norring et al., 2008).

Not all focus areas changed significantly within the 1-yr period. However, the lack of significant changes has to be interpreted with caution, as the relatively small sample sizes may not allow for a detection of changes. For example, overall lameness prevalence remained unaffected in the 3 groups, but variable success has been reported for lameness intervention. Our findings are in accordance with Bell et al. (2009) and Barker et al. (2012), who did not achieve improvements after 1 yr due to inadequate implementation. Compared with other focus areas, implementation of measures relating to leg health was also relatively low in the present study. In contrast, although baseline lameness prevalence was slightly lower, Brinkmann and March (2010) achieved a relatively high implementation rate, and leg health improved even after $1 \mathrm{yr}$. In our study, more than $50 \%$ of the implemented measures addressing leg health were occasional changes, such as regular claw trimming. However, additional management measures such as improvements in bedding and lying area, respectively, which are known to be beneficial for leg health (Main et al. 2012), were less frequently implemented. This could also have compromised improvements in leg health. Farmers often underestimate lameness prevalence (Whay et al., 2002; Barker et al., 2010; Šárová et al., 2011) and the possible health and welfare relevance as well as financial aspects of impaired leg health (Leach et al., 2010). However, understanding these factors is essential for achieving success, and action can only take place when a problem is detected (Whay and Main, 2010). For instance, Leach et al. (2013) reported how efforts in training farmers to score lame cows in their herds resulted in an improved detection. In our study, it was not possible to visit the farms for follow-up advice during the year after the implementation had started. This may have hampered the proper implementation and adaptation of measures, as highlighted by Brinkmann and March (2010).

The focus areas "lying comfort" and "social behavior/ HAR" were rarely chosen. Gratzer (2011) also reported that only 8 out of 39 farms implemented measures focusing on behavior, indicating that this topic was relatively new to farmers and of minor relevance compared with health issues. Additionally, the baseline situation in our study did not necessarily require interventions; for example, regarding the mean duration of lying down movements and the prevalence of animals lying outside the cubicles (Welfare Quality, 2009; Plesch et al., 2010). Similarly, the level of agonistic behaviors and avoidance distance at the feedrack as a measure of HAR were mostly within a satisfactory range (Windschnurer et al., 2008; Welfare Quality, 2009; Gratzer, 2011). 
Furthermore, temperament may be regarded as more important in extensively managed beef cattle than in dairy cattle (Le Neindre et al., 1996).

\section{CONCLUSIONS}

The aim of improving health and welfare of dairy cows was achieved for some focus areas. Udder health and cleanliness of teats improved significantly $1 \mathrm{yr}$ after farms had implemented changes in husbandry practices. Changes in management routines may have predominantly accounted for the effects of the interventions on udder health. We did not find evidence that the approach chosen led to an improvement of leg health. The 1-yr process of animal health and welfare planning, as carried out on the 34 farms, therefore appears to be a promising approach to improve some animal health issues. In particular, the participatory approach when discussing farm-specific aims and measures and the structured process seem to be crucial.

\section{ACKNOWLEDGMENTS}

The authors thank the farmers who participated in this study for their time and effort. This work was funded by a BOKU DOC Grant provided by the University of Natural Resources and Life Sciences (BOKU; Vienna, Austria).

\section{REFERENCES}

Ali, A. K. A., and G. E. Shook. 1980. An optimum transformation for somatic cell concentration in milk. J. Dairy Sci. 63:487-490.

Barker, Z. E., K. A. Leach, H. R. Whay, N. J. Bell, and D. C. J. Main. 2010. Assessment of lameness prevalence and associated risk factors in dairy herds in England and Wales. J. Dairy Sci. 93:932-941.

Barker, Z. E., J. L. Wright, R. W. Blowey, J. R. Amory, and L. E. Green. 2012. Uptake and effectiveness of interventions to reduce claw lesions in 40 dairy herds in the UK. Anim. Welf. 21:563-576.

Bell, N. J., M. J. Bell, T. G. Knowles, H. R. Whay, D. J. Main, and A. J. F. Webster. 2009. The development, implementation and testing of a lameness control programme based on HACCP principles and designed for heifers on dairy farms. Vet. J. 180:178-188.

Bennedsgaard, T. W., I. C. Klaas, and M. Vaarst. 2010. Reducing use of antimicrobials - Experience from an intervention study in organic dairy herds in Denmark. Livest. Sci. 131:183-192.

BMLFUW. 2012. Grüner Bericht 2012. The Austrian Federal Ministry of Agriculture, Forestry, Environment and Water Management, Vienna, Austria.

Brinkmann, J., and S. March. 2010. Animal health in organic dairy farming - Health state as well as development, application and evaluation of a preventive herd health planning concept. Doctoral Thesis. Georg-August-Universität Göttingen, Göttingen, Germany. (In German).

Clarkson, M. J., D. Y. Downham, W. B. Faull, J. W. Hughes, F. J. Manson, J. B. Merritt, R. D. Murray, W. B. Russell, J. E. Sutherst, and W. R. Ward. 1996. Incidence and prevalence of lameness in dairy cattle. Vet. Rec. 138:563-567.

Dippel, S., M. Dolezal, C. Brenninkmeyer, J. Brinkmann, S. March, U. Knierim, and C. Winckler. 2009. Risk factors for lameness in cubicle housed Austrian Simmental dairy cows. Prev. Vet. Med. 90:102-112.

Duncan, I. J. H. 1996. Animal welfare defined in terms of feelings. Acta Agric. Scand. Anim. Sci. 27:29-35.

Ellis, K. A., G. T. Innocent, M. Mihm, P. Cripps, W. G. McLean, C. V. Howard, and D. Grove-White. 2007. Dairy cow cleanliness and milk quality on organic and conventional farms in the UK. J. Dairy Res. 74:302-310.

Fraser, D., D. M. Weary, E. A. Pajor, and B. N. Milligan. 1997. A scientific conception of animal welfare that reflects ethical concerns. Anim. Welf. 6:187-205.

Gratzer, E. T. 2011. Animal health and welfare planning in Austrian organic dairy farms. Doctoral Thesis. University of Natural Resources and Life Sciences, Vienna, Austria.

Green, M. J., K. A. Leach, J. E. Breen, L. E. Green, and A. J. Bradley. 2007. National intervention study of mastitis control in dairy herds in England and Wales. Vet. Rec. 160:287-293.

Haskell, M. J., L. J. Rennie, V. A. Bowell, M. J. Bell, and A. B. Lawrence. 2006. Housing system, milk production, and zero-grazing effects on lameness and leg injury in dairy cows. J. Dairy Sci. 89:4259-4266

Huijps, K., T. J. G. M. Lam, and H. Hogeveen. 2008. Costs of mastitis: Facts and perception. J. Dairy Res. 75:113-120.

Ivemeyer, S., A. Maeschli, M. Walkenhorst, P. Klocke, F. Heil, S. Oser, and C. Notz. 2008. Effects of a two-year dairy herd health management programme on udder health, use of antibiotics and longevity. Schweiz. Arch. Tierheilkd. 150:499-505. (In German).

Ivemeyer, S., G. Smolders, J. Brinkmann, E. Gratzer, B. Hansen, B. I. F. Henriksen, J. Huber, C. Leeb, S. March, C. Mejdell, P. Nicholas, S. Roderick, E. Stöger, M. Vaarst, L. K. Whistance, C. Winckler, and M. Walkenhorst. 2012. Impact of animal health and welfare planning on medicine use, herd health and production in European organic dairy farms. Livest. Sci. 145:63-72.

Ivemeyer, S., M. Walkenhorst, F. Heil, C. Notz, A. Maeschli, G. Butler, and P. Klocke. 2009. Management factors affecting udder health and effects of a one-year extension program in organic dairy herds. Animal 3:1596-1604.

Kirchner, M. K., S. H. Westerath, U. Knierim, E. Tessitore, G. Cozzi, C. Pfeiffer, and C. Winckler. 2014. Application of the Welfare Quality ${ }^{\circledR}$ assessment system on European beef bull farms. Animal 8:827-835

Le Neindre, P., X. Boivin, and A. Boissy. 1996. Handling of extensively kept animals. Appl. Anim. Behav. Sci. 49:73-81.

Leach, K. A., E. S. Paul, H. R. Whay, Z. E. Barker, C. M. Maggs, A. K. Sedgwick, and D. C. J. Main. 2013. Reducing lameness in dairy herds-Overcoming some barriers. Res. Vet. Sci. 94:820-825.

Leach, K. A., H. R. Whay, C. M. Maggs, Z. E. Barker, E. S. Paul, A K. Bell, and D. C. J. Main. 2010. Working towards a reduction in cattle lameness: 1 . Understanding barriers to lameness control on dairy farms. Res. Vet. Sci. 89:311-317.

Main, D. C. J., K. A. Leach, Z. E. Barker, A. K. Sedgwick, C. M. Maggs, N. J. Bell, and H. R. Whay. 2012. Evaluating an intervention to reduce lameness in dairy cattle. J. Dairy Sci. 95:29462954.

Main, D. C. J., A. J. F. Webster, and L. E. Green. 2001. Animal welfare assessment in farm assurance schemes. Acta Agric. Scand. Anim. Sci. 51:108-113.

March, S., J. Brinkmann, and C. Winckler. 2014. Improvement of animal health in organic dairy farms through 'stable schools': Selected results of a pilot study in Germany. Organic Agric. 4:319-323.

Micheel, H. G. 2010. Quantitative empirische Sozialforschung. UTB, Stuttgart, Germany.

Norring, M., E. Manninen, A. M. De Passillé, J. Rushen, L. Munksgaard, and H. Saloniemi. 2008. Effects of sand and straw bedding on the lying behavior, cleanliness, and hoof and hock injuries of dairy cows. J. Dairy Sci. 91:570-576.

Pinheiro, J., D. Bates, S. DebRoy, D. Sarkar, and R Core Team. 2014. nlme: Linear and Nonlinear Mixed Effects Models. R package version 3.1-118, http://CRAN.R-project.org/package=nlme.

Plesch, G., N. Broerkens, S. Laister, C. Winckler, and U. Knierim. 2010. Reliability and feasibility of selected measures concerning 
resting behaviour for the on-farm welfare assessment in dairy cows. Appl. Anim. Behav. Sci. 126:19-26.

Plesch, G., and U. Knierim. 2012. Effects of housing and management conditions on teat cleanliness of dairy cows in cubicle systems taking into account body dimensions of the cows. Animal 6:1360-1368.

R Core Team. 2013. A language and environment for statistical computing. R version 3.0.2. R Foundation for Statistical Computing, Vienna, Austria.

Roche, J. R., N. C. Friggens, J. K. Kay, M. W. Fisher, K. J. Stafford, and D. P. Berry. 2009. Body condition score and its association with dairy cow productivity, health, and welfare. J. Dairy Sci. 92:5769-5801.

Šárová, R., I. Stěhulová, P. Kratinová, P. Firla, and M. Špinka. 2011. Farm managers underestimate lameness prevalence in Czech dairy herds. Anim. Welf. 20:201-204.

Schreiner, D. A., and P. L. Ruegg. 2003. Relationship between udder and leg hygiene scores and subclinical mastitis. J. Dairy Sci. 86:3460-3465.

Sibley, R. J. 2002. NDFAS and herd health plans. Vet. Rec. 150:255.

Tremetsberger, L., and C. Winckler. 2015. Effectiveness of animal health and welfare planning in dairy herds: A review. Anim. Welf. 24:55-67.

Vaarst, M., C. Winckler, S. Roderick, G. Smolders, S. Ivemeyer, J. Brinkmann, C. M. Mejdell, L. K. Whistance, P. Nicholas, M. Walkenhorst, C. Leeb, S. March, B. I. F. Henriksen, E. Stöger E. Gratzer, B. Hansen, and J. Huber. 2011. Animal health and welfare planning in organic dairy cattle farms. Open Vet. Sci. J. $5: 19-25$.

Welfare Quality. 2009. Welfare Quality ${ }^{\circledR}$ Assessment Protocol for Cattle. Welfare Quality Consortium, Lelystad, the Netherlands.

Whay, H. R., Z. E. Barker, K. A. Leach, and D. C. J. Main. 2012. Promoting farmer engagement and activity in the control of dairy cattle lameness. Vet. J. 193:617-621.

Whay, H. R., and D. C. J. Main. 2010. Improving animal welfare: Practical approaches for achieving change. Pages 227-251 in Improving Animal Welfare: A Practical Approach. T. Grandin, ed. Colorado State University, Fort Collins.

Whay, H. R., D. C. J. Main, L. E. Green, and A. J. F. Webster. 2002. Farmer perception of lameness prevalence. Pages 355-358 in Proc. 12th Int. Symp. Lameness in Ruminants, Orlando, FL. J. K. Shearer, ed. 12th Int. Symp. Lameness in Ruminants Organizing Committee, Orlando, FL.

Whay, H. R., D. C. J. Main, L. E. Green, and A. J. F. Webster. 2003. Assessment of the welfare of dairy cattle using animal-based measurements: Direct observations and investigation of farm records. Vet. Rec. 153:197-202.

Wiggans, G. R., and G. E. Shook. 1987. A lactation measure of somatic cell count. J. Dairy Sci. 70:2666-2672.

Windschnurer, I., C. Schmied, X. Boivin, and S. Waiblinger. 2008. Reliability and inter-test relationship of tests for on-farm assessment of dairy cows' relationship to humans. Appl. Anim. Behav. Sci. 114:37-53. 